\title{
Teachers' narratives: A source for exploring the influences of teachers' significant life experiences on their dispositions and teaching practices
}

\author{
Servet Altan*, Jennie Farber Lane \\ Bilkent University, Graduate School of Education, 06100, Çankaya, Ankara, Turkey
}

\section{H I G H L I G H T S}

- Teachers' stories provide key resources for effective teacher education programs.

- Teachers' significant life experiences and dispositions influence teaching practice.

- Supportive learning environments influence teachers' dispositions positively.

- Experiences related to personal attributes influence teachers' dispositions.

\section{A R T I C L E I N F O}

\section{Article history:}

Received 25 September 2017

Received in revised form

11 April 2018

Accepted 22 May 2018

Available online 26 May 2018

\section{Introduction}

Teachers are change agents in societies. Class size, administration, and resources are important, but it is teachers who have the most influence on student achievement (Brophy \& Good, 1986; Cruickshank, Jenkins, \& Metcalf, 2009; Darling-Hammond, 2006, 2000; Lasley, Seidentop, \& Yinger, 2006; Tellez \& Waxman, 2006). With technological and societal demands of the 21st century, effective teacher education is even more critical. Among other things, teachers need to be disposed to deal with rapid changes and innovations. Teachers' dispositions are also important for many other aspects of students' learning experiences. Dispositions have been linked to teachers' behaviors and practices (Diez, 2007a; Fang, 1996; Serdyukov \& Ferguson, 2011), to their beliefs, knowledge, and characteristics, and have long-lasting impact on instructional practices (Hong, Greene, \& Hartzell, 2011).

Given the importance placed on dispositions, it is little wonder

\footnotetext{
* Corresponding author.

E-mail addresses: serveta@bilkent.edu.tr (S. Altan), jennie.lane@bilkent.edu.tr (J.F. Lane).
}

that there has been a call for teacher education programs to foster constructive teaching dispositions. In 1992, the Interstate New Teacher Assessment and Support Consortium (INTASC) and later in 2008, the National Council for Accreditation of Teacher Education (NCATE) emphasized the importance of dispositions in teacher education programs. The Council of the European Union for teacher education included dispositions among its priorities for teacher achievement (Caena, 2011). Teacher education programs "can influence the creation and revision of dispositions" (Nelsen, 2015, p. 6). Therefore, it is important to understand what dispositions are and what contributes to their development.

\section{Theoretical framework}

Although there are many different ways to define dispositions, in general they are individual's tendencies to act in a particular manner (Borko, Liston, \& Whitcomb, 2007, p. 361). To identify and understand these "tendencies to act," the authors of the current paper favor the Deweyan term "habit" (Dewey, 1922, p. 32). Other researchers have used the term habit to describe dynamic and revisable teaching attitudes and behaviors (Altan et al., 2017; Costa \& Kallick, 2014; Dottin \& Sockett, 2006; Richhart, 2001; Thornton, 2006).

In the current study, a teacher's disposition is considered to be comprised of clusters of mindful and thoughtful habits that can evolve through constructive experiences. To categorize habits, the authors relate to Habits of Mind as outlined by Costa and Kallick (2000) who identified and described the following 16 habits of mind: (i) applying past knowledge to novel situations, (ii) creating, imagining, and innovating, (iii) finding humor, (iv) gathering data through all senses, (v) listening with understanding and empathy, 
(vi) managing impulsivity, (vii) metacognition (thinking about thinking), (vii) persisting, (xi) questioning and problem posing, (x) remaining open to continuous learning, (xi) responding with wonderment and awe, (xii) striving for accuracy, (xii) taking responsible risks, (xiv) thinking and communicating with clarity and precision, (xv) thinking flexibly, and (xvi) thinking interdependently.

The authors refer to the Theory of Experience as described by Dewey (1938) to explain how dispositions are developed. In this theory, life can be viewed as the experiential continuum where every experience leads to change and growth (albeit positive or negative). As the experiences are repeated and enforced, individuals develop habitual ways of thinking to interact with the experiences. Fig. 1 illustrates how these habits are developed and become a disposition (a cluster of habits of minds). The habits of mind in turn can be used to address new and different situations, such as those teachers face in their daily teaching practice.

As noted in the introduction, teacher education programs have been encouraged to focus on dispositions. When teachers' dispositions are viewed as habits of mind, teacher education programs can provide constructive experiences to help develop effective teaching dispositions (Dottin, 2009; Nelsen, 2015). But, which educative activities can contribute to development of effective teaching dispositions? It is beyond this study to study all kinds of habits, dispositions, and experiences. Instead, the authors chose to focus on five teachers who were observed by the lead author to exhibit many of Costa and Kallick's habits of mind. These observations were confirmed through a peer review of the participants. Through qualitative analysis of these teachers' narratives about their significant life experiences, the researchers learned which events the teachers believed contributed to the construction of their habits of mind and are reflected in their teaching practices. The authors discuss how integration of these experiences in teacher education programs may provide opportunities for fostering constructive habits of mind and anticipate further research to explore the feasibility and outcomes.

\subsection{Researching teachers' lives: significant life experience research}

The relationship between life experiences and learning has been researched by a number of educators and psychologists (Dewey, 1938; Jarvis, 1987; Kolb, 1984; Merriam \& Clark, 1993; Mezirow, 1990). In the literature, several researchers have investigated the influences of the family environment, especially parents, in nurturing personal dispositions (Becker, 1964; Cabrera \& Tamis-
Lemonda, 2013; Egberts, Prinzie, Dekovic, de Haan, \& van den Akker, 2015; Goleman, 1995; Lamb, 2010; Mayer \& Salovey, 1997; Nettle, 2008; Rosenberg \& Wilcox, 2006; Suzuki, 2005). Parental attitudes and values are considered to be among the most significant influences on children's development (Langelholf, Komdeur, \& Oldehinkel, 2016) and childhood is the most malleable period in terms of identity formation (Knafo \& Schwartz, 2004). Parents are teachers and role models for the development of children's thoughts, emotions, and behaviors (Greenfield \& Suzuki, 1998).

Although there is extensive research conducted about the influences of the role of family environment on the development of personal dispositions, there have been fewer studies related to the role of teachers' significant life experiences on the development of their teaching dispositions and practice. Goodson and Gill (2014) refer to teachers' significant life experiences and other background factors as "key ingredients" of a person and that those key ingredients shape teaching practices (p. 13). Butt, Townseed and Raymond (1990) suggest narratives focusing on childhood, adolescence, young adulthood, and other phases of development can bring forth an understanding of teacher dispositions (p. 7).

\section{Study purpose and research questions}

This study used narrative inquiry as methodology to investigate the influences of significant life experiences on the dispositions and teaching practices of five female teachers. Significant life experiences are the ones that "personally affect the individual and are subjectively valued by the individual" and the significant experience results in "expansion of skills and abilities, sense of self, or life perspective, or it precipitates a transformation that involve the whole person" (Merriam \& Clark, 1993, p. 182).

The narrative texts, which are the outcomes of interaction between the researchers and participants, were analyzed using a conceptual framework developed by the Altan et al., 2017 in order to contemplate the influences of participants' significant life experiences on their dispositions. This framework was created to provide theoretical grounding to Habits of Mind proposed by Costa and Kallick (2000). The authors drew upon intelligent behaviors associated with the habits of mind and used a review of the literature to identify established educational theories that explained the behaviors. Rather than seeking a cause-and-effect relationship between the significant life experiences and participants' dispositions, the researchers used the conceptual framework to contemplate potential relationships between participants' significant life experiences and their dispositions. The research questions that

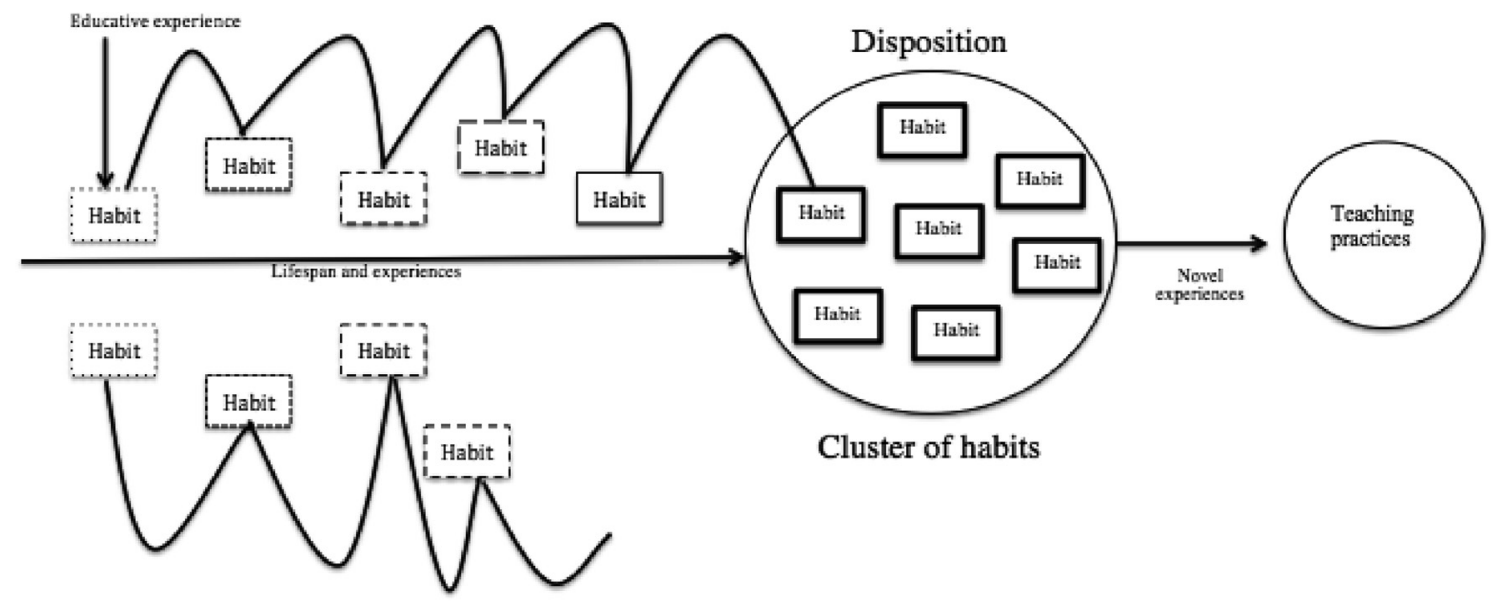

Fig. 1. A conceptual map displaying the connections between a teacher's disposition [comprised of cluster of habits], experiences and teaching practices. 
guided this study are as follows:

- Which significant life experiences, revealed from participants' narratives, contributed to participants' dispositions?

- What do the narratives of five teachers reveal about the contribution of participants' significant life experiences to their dispositions?

- Based on the findings from participants' narratives, in what ways did participants' significant life experiences contribute to their teaching practices?

\section{Context and participants}

Learning about people's lives and interpreting their experiences requires that narrative researchers consider the various contextual aspects that helped produce narrative identities. These aspects may include participants' physical environment, ethnic, historical, political, economic contexts, and gender (Bruner, 1990; Polkinghorne, 1988). Spector-Mersel (2011) discusses that as narrative researchers gather stories as data, the context may be easier to ascertain; the holistic aspect of stories help make it possible for researchers to communicate the context to the reader. SpectorMersel explains that context in narrative research can be "macro, micro, and immediate" (p. 173). Macro context refers to where the narrative identities are produced (participants' living environments) and micro context refers to how they are produced (events that occurred in the past). A third context for narrative research is the immediate context: the actual time and place of the participants' shared stories. The current study focused on the macro contexts (i.e., physical, economic, social, geographical aspects that helped participants develop their identities) and micro contexts (i.e., participants' significant life experiences) that are provided through their narratives.

The researchers purposefully selected five female teachers who were observed by lead author to display some or all the sixteen habits of mind in and out of the work context. These observations were confirmed through a peer review of the participants. As Vazire (2010) suggested we are far from observing ourselves perfectly accurate and others (outsiders: friends, coworkers, family members) are at least as accurate as the self to describe what a person is like. Therefore, two close peers of each participant were asked to complete a survey asking which habits of mind they agreed were exhibited by the teachers. Another reason these participants were selected was because they were open to sharing their life stories, which helped the researcher investigate the influences of significant life experiences on participants' dispositions and teaching practices through narrative inquiry.

At the time of the study, all participants were working as teachers at prestigious schools. Four of the participants were working at a well-known private school in Ankara, Turkey and one of the participants was working for a rigorous public school. The study took place in Ankara, Turkey over the course of a year. The interviews were conducted by the lead author at a time and place convenient for the participants; sometimes this was their home and sometimes it was a café where participants felt comfortable sharing their stories. Participants gave their consent before the study began. They were provided with a letter that detailed the purpose and stages of the study. Participants chose a pseudonym that was used throughout the study. Following is a character sketch (i.e., brief description) of each participant, based on their stories.

Ada. Ada comes from a family of six. She has been a language teacher for twenty-three years. She also worked as a secretary in government offices for a short period before becoming a teacher. Ada moved to Ankara, the capital city of Turkey, for her university education and stayed there afterwards. She has a few hobbies that help her to unwind such as jogging, travelling, collecting stones and old books, and writing. Ada defined her parents as authoritative.

Gülșen. Gülșen has been a classroom teacher for thirty-eight years. She was born in a small city in the eastern part of Turkey and then moved to Ankara, the capital, during the late 1990s. She defines herself as a continuous learner. Gülșen developed a strong reading habit when she was eleven. She reads every day. She enjoys reading national and global classical pieces of writing. There are a few hobbies that help Gülşen to "disconnect with the reality of life and help me attain a peaceful mind." These hobbies are: swimming, walking in nature, travelling (even to local places that she has been to before), knitting, gardening, painting stones with different cultural and historical images, and making dolls using wooden spoons and wool. Gülșen defined her parents as authoritative.

Pelin. Pelin comes from a family of two. She has been a teacher for thirty-nine years. She states that she was always very fond of her father. She has a brother, but they have not seen each other for several years. She has got a strong habit of reading. Pelin enjoys reading realist, surrealist, and research-based writing. She adds that she enjoys poetry as well. She reads every day. When it comes to her hobbies, Pelin says: "I always have some kind of collections. For example: I have a collection of notebooks that I use to write poems in and bookmarks. I enjoy nature walks, dancing, swimming and knitting a lot." Pelin defined her parents as authoritative.

Ekin Su. Ekin Su has been a Visual Arts teacher for thirty-five years. She comes from a family of five. She loves reading. A recent hobby of hers is travelling. She identifies herself as the perfect tourist because she reads about the geography, culture and history of the places she visits before the trip starts. She makes sure to visit all of the art museums in the places that she visits and buys items from their stores as souvenirs or to use as teaching materials. After her retirement, she started writing about the places she has travelled to. Ekin Su has a repertoire of her own paintings and she has opened individual exhibitions a number of times. She defines her parents as authoritative.

Mor. Mor comes from a family of two. She has been a teacher for nineteen years. She taught at schools in different regions of Turkey and Cyprus. She teaches at a primary school and she has also been a guitar teacher for almost ten years. Prior to becoming a classroom teacher she taught geography for two years. She has also been a professional tour guide since 1995 . Mor enjoys travelling a lot and so far, she has been to over 80 countries. She also enjoys collecting cultural objects from the places that she visits and she has a large collection of photos. Mor defines the parenting style of her parents as a combination of authoritative (mother) and uninterested (father).

\section{Methodology and methods}

The researchers used narrative inquiry as methodology to identify participants' significant life experiences and to investigate potential influences of these experiences on their dispositions and teaching practices. The conceptualization of narrative inquiry arises from the Deweyan (Dewey, 1938) notion that life is education. Narrative inquiry studies use stories to investigate the ways humans experience the world (Connelly \& Clandinin, 1990). Narrative inquiry has been used to probe into teachers' identity construction, including the role of personal, cultural, historical and social events (Beattie, 2000; Cavendish, 2011; Chan, 2012; Court, Merav, \& Ornan, 2010; Dickinson, 2012). By sharing their stories, teachers explain how emotions play a key role in their professional growth (Day \& Leitch, 2001), identify critical events that may have affected their perspectives (Johnson \& Golombek, 2002), and explore influential experiences that have affected their practice 
(Orland-Barak \& Maskit, 2011).

Narrative inquiry is classified under qualitative inquiry and lies within the interpretive paradigm. According to this paradigm, reality is socially constructed and the researcher relies on the "participant's view of the situation being studied" (Creswell, Clark, Gutman, \& Hanson, 2003, p. 8). This viewpoint helps to explain and make meaning, rather than determine a causal relationship. The intent of the researcher is to inductively analyze the data and generate a theory, a pattern of meanings (Creswell, Plano Clark, Gutmann, \& Hanson, 2003). The aim of narrative research is not to find one generalizable truth but to "sing up many truths/narratives” (Byrne-Armstrong, 2001, p. 112). Therefore, narrative researchers are not concerned about generalizability of the findings in the positivist sense, which typically refers generating findings from the study sample to the entire population (Myers, 2000). Instead, like other qualitative inquiry researchers, narrative researchers seek for practical and functional uses rather than cultivating persistent laws (Stake, 1978, p. 70).

From the perspective of narrative inquiry, individuals are storytelling organisms and narrative researchers deal with how human beings experience the world and how they make meaning of their experiences (Connelly \& Clandinin, 1990). Human beings understand the world around them based on their own construction and reconstruction of personal and social experiences (Guba \& Lincoln, 1994). To gain an understanding of this construction, it is the narrative researchers' role to collect stories, interpret them, and construct the narrative texts. The researcher is seen as the main data collection tool and participants become co-inquirers. As narrative inquirers attend to their participants' lives, participants' stories become a part of researcher's ongoing inquiry about the phenomenon under study (Lindsay \& Schwind, 2016). "Narrative inquirers see themselves and their participants as co-composing each aspect of the inquiry" (Clandinin \& Huber, 2012, p. 5) and collaboration between researcher and participants take place over time, in a place or series of places (Connelly \& Clandinin, 2000, p. 20 ). It is the researcher's task to make sure that all voices are heard equally.

Narratives are the form of representation that describes participants' experiences and representation of narrative data can take many forms. It can be in the form of field notes, interview transcripts, photos, metaphors, letters, and diaries, autobiographical/ biographical pieces of writing, newsletter, and personal philosophies (Connelly \& Clandinin, 1990). The data are usually based on large texts or life stories which could be presented as life stories themselves. "Narratives are understood as stories that include a temporal ordering of events and an effort to make something out of those events" (Sandelowski, 1991, p. 162). For the current study, narratives were the outcomes of interaction between the researchers and participants (Polkinghorne, 2007) and narratives were constructed based on participants' stories. The narratives were selected and given cohesion to make them flow and give a sense of linearity. The researcher used emerging categories, themes, and life experiences from participants' stories to compose and restructure the narratives. Therefore, participants' [teachers'] stories told to researcher were for research purposes rather than stories teachers spontaneously told each other (Carter, 1993, p. 8). Given that the narratives are based on participant memories, they can be biased, influenced, or flawed. Retrieving past experiences from autobiographical memory may include falsifiable and/or reconstructed version of the past experiences (McAdams, 2001). To ensure the trustworthiness of the data, the researchers followed recommendations of other narrative inquirers. As narrative data are subjective and context-specific, Riessman (1993) suggests the criteria for trustworthiness should rely upon persuasiveness and coherence. It is the responsibility of narrative researcher to "convince the readers of the likelihood that the claim can serve as a basis for understanding of and action in the human realm" (Polkinghorne, 2007, p. 476). In an effort to validate and confirm, however, Clandinin and Connelly (1990) caution narrative researchers should not try to "squeeze the language of narrative criteria into a language created for other forms of research" (p. 7). As much as possible, the voices and expressions of the narrators need to be heard. Therefore, it is important for the researcher to share the generated texts with the participants (i.e., member checking) to confirm whether the words captures the essential features of their experience and feelings; "if it does not, [the participants] can suggest alterations or expansions of the text to more clearly display their meaning" (Polkinghorne, 2007, p. 482).

Using an iterative research process, the researchers returned to the generated texts of the participants to gain clarification and further insights into the study's research questions. In addition to member-checking, the authors used expert validation, and reflection. Throughout the study, the authors met with an educational psychologist and other experienced teacher educators to discuss how to best interpret the data gathered before finalizing the findings. Finally, the lead author kept a reflexive journal. This reflective process helped build his capacity to record, interpret, and report narrative data before and during the research process. Fig. 2 illustrates how these elements of narrative inquiry were incorporated into the research design of the current study.

\subsection{Data collection}

This study used one of the main data collection tools in narrative inquiry: the unstructured interview. Rather than a set of prescribed questions, a more open format was used to prompt participants to retrieve significant life experiences that potentially contributed to their dispositions. Three in-depth interviews were conducted with each participant over the course of a year. Each interview lasted between one and $2 \mathrm{~h}$ and was recorded with permission of the participants. The interviews built upon each other and were intended to provide participants with opportunities to recall, reflect, infer, and inspect. Through these three interviews, data collection and data analysis processes were iterative because the narratives and thematic analysis of the narratives were returned to the participants for them to check and discuss more deeply.

The first interview was designed to probe into participants' significant life experiences, which constituted their life stories based on autobiographical memories. Autobiographical memory is the recollection of memories that people have about personal events that are experienced at a specific moment in time (Brewer, 1986). Events that are highly significant produce more vivid memories unlike events of low importance (Herlihy, Jobson, \& Turner, 2012) and unstructured interview questions help people recall significant memories more openly, with less influence or bias (Chawla, 2010). The participants were asked to bring any objects, photos, diaries, letters, notes or artifacts that were important to them and would help them retrieve memories. With this object at hand, the following open-ended prompt was given to all participants for the first interview:

Imagine that your life has been a journey from birth until today. Talk about your life experiences at home, school, or as a learner during this life journey, which had an impact on or contributed to your ways of thinking. You can stop any time you feel uncomfortable.

After this interview, the researchers transcribed the stories. Each story was reviewed separately, categorizing information and looking for themes. The second interview served the purposes of 


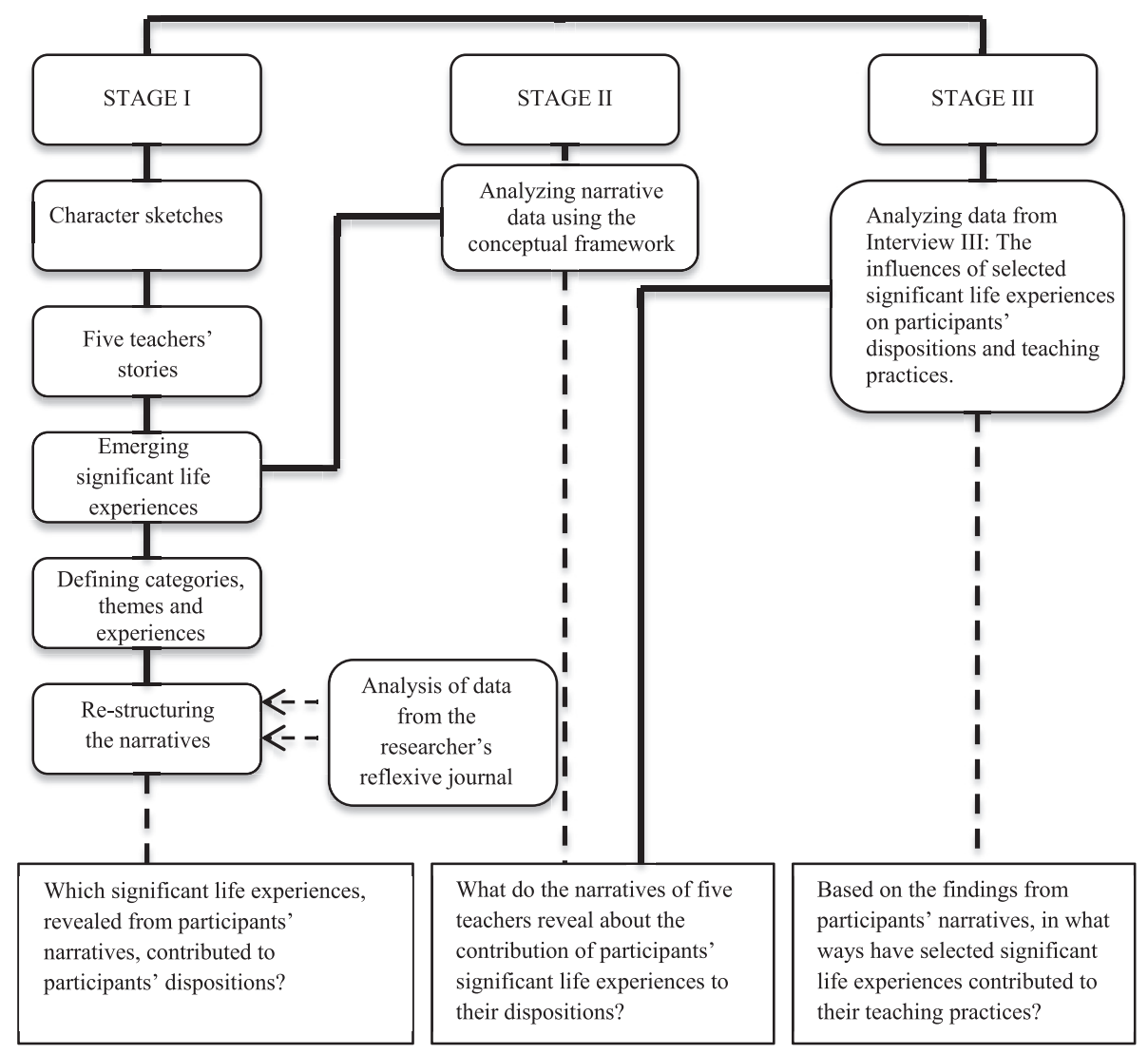

Fig. 2. Visual model of research design.

member-checking of the narratives and probing deeper into the relationships among the teachers' significant life experiences and their dispositions. Before inquiring the perceived influences of participants' significant life experiences on their dispositions, the researcher clarified the concept of dispositions in order to ensure there was a common understanding. The participants were given sufficient time to review and reflect on each narrative and indicate changes if any. The researchers shared all the themes that appeared across all five narratives and checked with each participant to see if they agreed with how their experiences related to the theme and if there were any life experiences that they had not mentioned yet, but they regarded as significant. This helped the researchers to reconstruct the narratives and revise the themes that emerged from the narratives. After getting participants' feedback on significant life experiences, the researcher provided the following guiding questions, which aimed to probe deeper into the contribution of significant life experiences to their dispositions.

- Which experiences are you choosing as significant? Why?

- In what way do you think this experience contributed to your dispositions?

o Did this experience result in forming a new, in expanding, and/or in changing a way of thinking and behaving [a disposition]?

The lead author arranged a final interview with each research participant. This interview served the following purposes: to obtain participants' review and feedback on the re-constructed narratives for final review and to ask participants to probe deeper into the influences of selected significant life experiences on their teaching dispositions and practices. The researchers selected the following significant life experiences to discuss with teachers: travelling, professional development, reading, spending time in nature, and having hobbies. These were chosen because they involved activities that could most feasibility be incorporated into a teacher education program (compared to experiences related to parenting style, for example). The following questions were asked during the final interview:

- In what ways did these life experiences contribute to your current dispositions?

- In what ways did these life experiences contribute to your teaching practices?

\subsection{Data analysis}

For this study, data analysis started with a general question: What do the extensive narratives tell the researcher? The researchers analyzed the data gathered in three stages. The first stage entailed the lead author, in consultation with the co-author and other expert reviewers, identifying categories and themes and conducting a thematic analysis of interview data to produce five narratives. The authors used Clandinin and Connelly's (2000) three-dimensional approach to analyze the narrative data. This approach involves Dewey's theory of experience along with the role of personal and social interactions. Data analysis entailed reading and re-reading the interview transcripts, which were then colorcoded for the elements that included information about the life experiences such as people, actions, and outcomes. An in vivo coding technique was used to label the sections of data. The purpose of this coding strategy is to ensure that concepts stay as close 


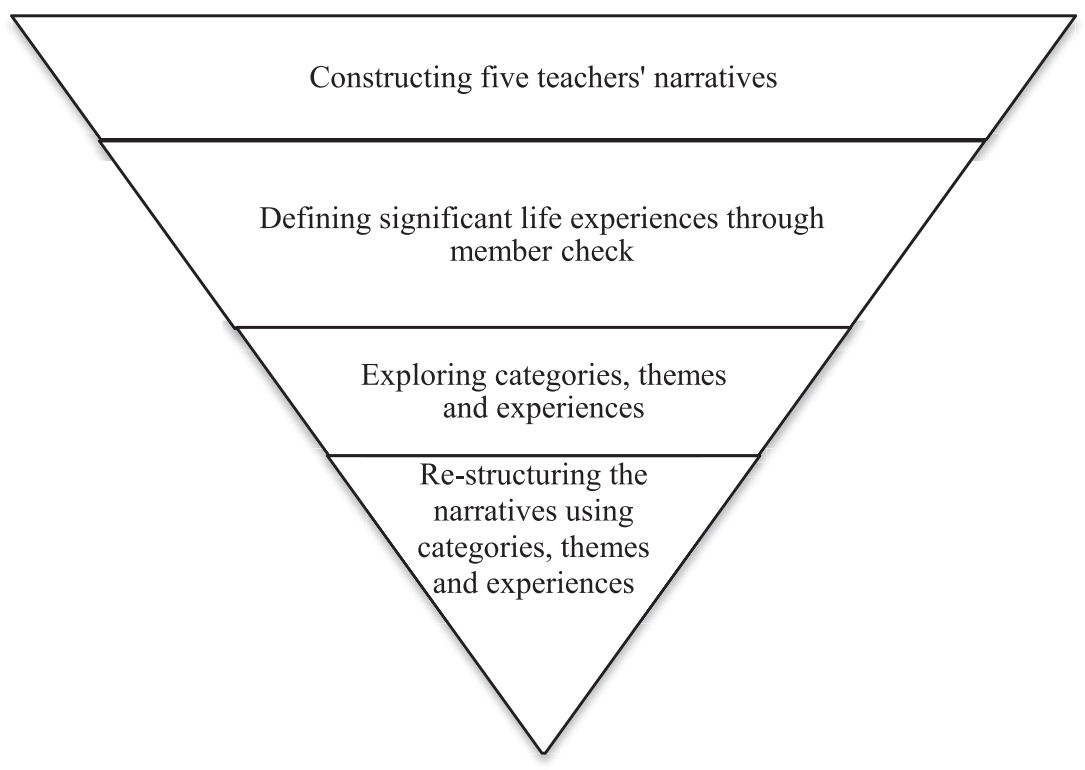

Fig. 3. Process of narrative data analysis to construct the narrative texts.

as possible to participant's own words or phrases. The coding process helped identify, categorize, and sequence the significant experiences. The researchers utilized Riessman's (2008) thematic approach to focus on conceptual groupings and relationships among the narrative texts. Each narrative was then restructured around the emerged categories, themes, and experiences (see Fig. 3).

For the second stage of data analysis, the researchers used the conceptual framework developed by Authors (2017) to identify the potential influences of participants' significant life experiences on their dispositions as sixteen Habits of Mind (Costa \& Kallick, 2000). The framework applies intelligent behaviors associated with the dispositions and relates them to educational theories established in the literature. In addition to the framework, a review of the literature related themes from the narrative texts to findings from other studies was conducted.

The third stage of data analysis aimed to probe deeper into the influences of selected significant life experiences (i.e., travelling, reading, spending time in nature, having hobbies) on participants' teaching dispositions and practices. At this time, the participants were given the key themes revealed during the study and asked to reflect on if and how they influenced their teaching dispositions and practices. After each interview was reviewed extensively and member checked, their experiences were compiled under the themes and condensed into a brief summary format. The authors related each participants' narratives to the emerging themes and then cross-referenced the narratives to compare and contrast commentaries. With such an approach to qualitative data, the researcher aimed to discover consistencies and inconsistencies within and across transcripts.

\section{Findings}

The results of the analysis of narrative data revealed that participants' significant life experiences consist of experiences related to two categories: Learning Environments and Personal Attributes. Learning Environments refers to diverse physical locations, contexts, and cultures in which individuals develop personally. More specifically Learning Environments refer to participants' home and school environments, and the neighborhood in which the participants grew up. Personal Attributes are the attributes or characteristics of a person that may have acquired as a result of significant experiences that the person purposefully initiated. For each category, the authors examined the narratives and conferred with expert reviewers to identify underlying themes and key experiences. The diagram in Fig. 4, based on an atom, illustrates the two categories and the themes. In this diagram, the orbiting electrons represent Learning Environments and the nucleus includes an individual's Personal Attributes.

The researchers purposefully chose to discuss five life experiences in detail: the family environment and the four attributes related to travelling, having hobbies, reading, and spending time in nature. The reasons of this choice are summarized below:

a) All participants considered their experiences related to family environment as the most significant experiences, which potentially contributed to their dispositions.

b) When teachers' dispositions are viewed as malleable entities, these life experiences can be used as strategies to develop effective dispositions (Diez, 2007a; 2007b).

\subsection{Experiences related to learning environments and dispositions}

The results of narrative data analysis indicated that experiences related to Learning Environments were the most significant for all participants. Learning environments refer to developing personally through attributes of the surrounding environments that influence individuals, including experiences related to family environment, school environment, and experiences related to neighborhood. Within this category, the analysis of the narratives revealed that experiences related to family were the most significant life experiences for all participants and they all experienced supportive family environment whether with a single or both parents.

The analysis of the narratives showed similarities among the family environments of five participants. All five participants described the parenting styles of their parents as "authoritative." They described the attitudes of their parents to be supportive, permissive, responsive, and democratic. The participants also noted that their parents, while being kind and caring, had firm rules and 


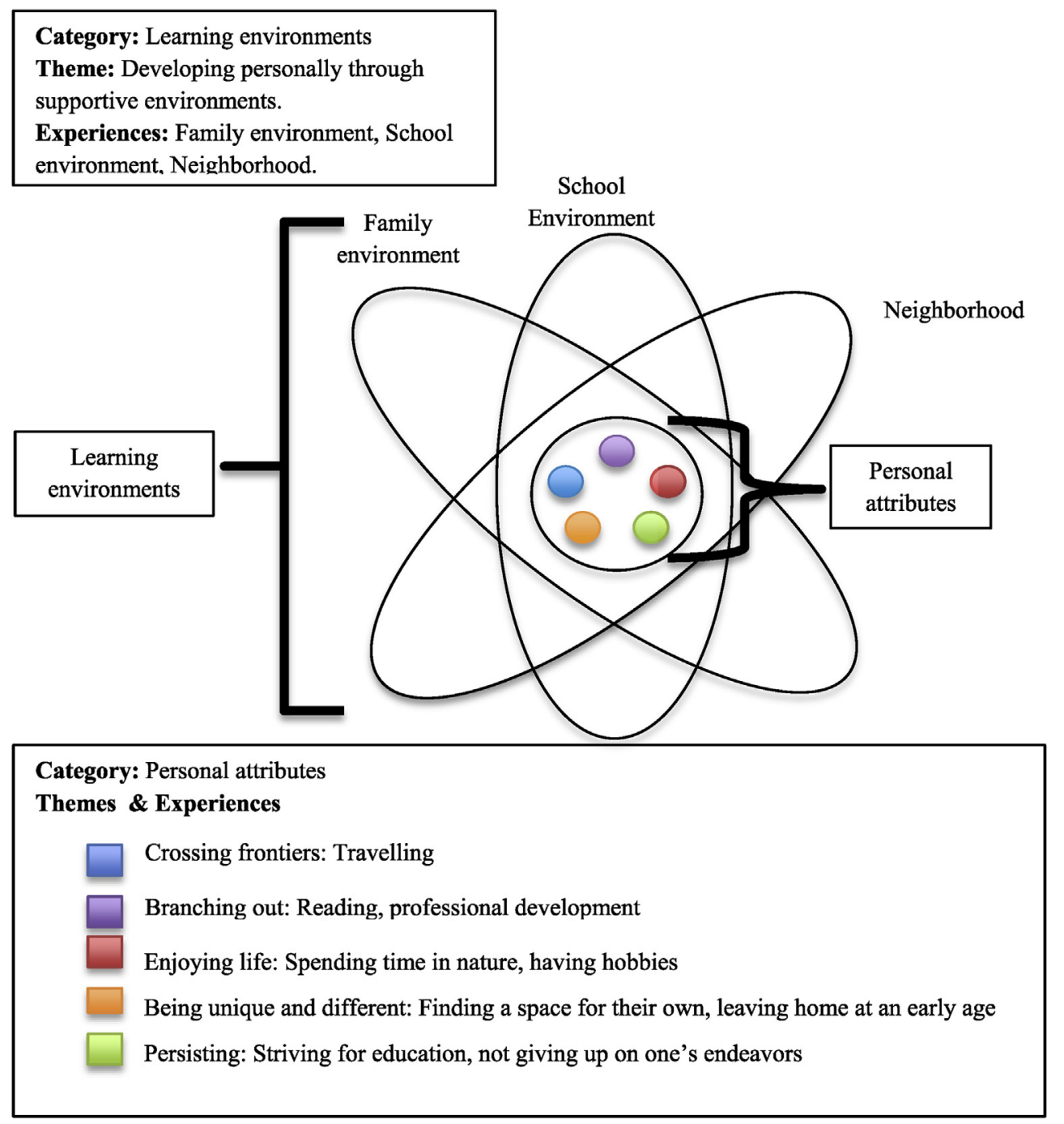

Fig. 4. Emerged categories, themes, and experiences from participants' narratives.

high expectations. These attributes of the family environment indicated that participants observed and experienced supportive behaviors that would help them develop personally in a variety of ways (i.e., emotionally and intellectually).

- "My parents encouraged me to see the bright side" (Gülșen).

- "My parents valued education and provided equal opportunities for everyone in the family" (Gülșen).

- "My parents were sensitive towards the needs of others" (Gülșen).

- "My parents loved and trusted me" (Pelin).

- "My parents would enjoy life through hobbies and social gatherings" (Pelin).

- "My parents were sensitive to the needs of others in our neighborhood" (Ekin Su).

- Reading was found to be a common feature of the family environment.

- "My parents would read a lot" (Ada).

- "My parents would read a lot for joy. We used to have reading corners where everybody read ... and my parents would buy books as presents for me" (Pelin).

Ada, Gülșen, Pelin, and Ekin Su described both of their parents as having positive outlooks, senses of humor, and valuing education. Mor was the exception, describing her father, as "uninterested who would ignore his children's needs." The other participants indicated their father played an influential in their lives and shared the following comments:

- "He was democratic. He created family parliament" (Ada).

- "He did not impose his own political views. Instead, he let us choose whatever we wanted to support" (Ekin Su).

- "He was open to discussions" (Pelin).

- "He was supportive of higher education. He would sell his clothes and spend that money for our education expenses" (Ada).

- "He taught us how to stay strong and he encouraged family relations based on love" (Ada).

Since all the participants in the study were female, it was important to consider the development of participants' dispositions in relation to father-daughter relationships. It is beyond the scope of the current study to investigate and report on fatherdaughter relationships. Other studies have investigated this relationship and the role on of the father on his daughter's personality and life satisfaction (e.g., Secunda, 1992). Allgood, Beckert \& 
Peterson (2012) claim that engaged father-daughter relationship plays an important role on daughters' self-esteem and life satisfaction in later stages of life. The results of their study indicated that nurturing types of father involvement during adolescence is likely to have a positive impact on their daughters' self-esteem and life satisfaction during their young adult years. Although this study did not aim to investigate any cause-effect relationships between Learning Environments and dispositions, the researchers intended to investigate the potential contributions of significant life experiences on participants' dispositions. It also does not posit that one parent is more influential than the other. In Mor's case the mother was more influential. Positive parenting from mothers may be associated with a safe and warm environment (Langelholf et al., 2016). This is consistent with what was depicted in the narratives, especially Ekin Su who described her mother as nurturing and emotional.

To examine how the Learning Environments and underlying themes may have influenced the development of participants' dispositions, the researchers applied the conceptual framework developed for the study. The researchers examined the narrative texts and identified intelligent behaviors that were described by the participants. Relating these behaviors to Costa and Kallick's (2000) sixteen Habits of Mind, the researchers could infer that Learning Environments may contribute to the following dispositions: finding humor, listening with understanding and empathy, managing impulsivity, remaining open to continuous learning, responding with wonderment and awe, persisting, thinking flexibly, and thinking interdependently.

\subsection{Experiences related to personal attributes and dispositions}

Within the category of Personal Attributes, the authors used the words and expressions of the participants' narratives to identify and label five themes as shown in Table 1.

Within the first three themes, the researchers identified four key experiences mentioned most often by the participants. These were experiences that were discrete and believed by the authors as most feasible to include in a teacher education program: Reading, travelling, having hobbies, and spending time in nature. As with the Learning Environments, the conceptual framework was used to identify dispositions that may have been developed through these experiences. The following dispositions were revealed through the analysis: listening with understanding and empathy, remaining open to continuous learning, responding with wonderment and awe, striving for accuracy, thinking flexibly. Furthermore, teachers were asked to reflect on how the experiences may have contributed to their teaching practice.
Travelling. The participants considered travelling as one of the most noteworthy experiences that potentially contributed to their dispositions in a variety of ways. The participants mostly considered travelling as a way to explore new cultures and sometimes just to have fun. This finding is consistent with the some literature as travelling is grouped under "restorative activities" and associated with psychological well-being (Pressmen et al., 2009). However, the influences of travelling on individuals have not gained much attention yet. The teachers in the study could identify how travelling may have influenced their teaching practice. They considered travelling not only as a cultural exchange but also as a valuable educational opportunity. Travelling influenced their way of communication with their students positively and helped them build empathy and communication effectively with others from different cultures. Exposure to another culture by travelling also influenced the classroom culture in a positive way.

Reading. The analysis of narrative data revealed that all participants were brought up in a home environment where reading was highly valued. They associated reading mostly with branching out, expanding, going into new areas, remaining open to continuous learning, developing communication skills, developing understanding and empathy toward others, and enjoyment. Regarding their teaching practice, the participants discussed how reading helped them become more effective communicators with their students and they considered reading as a way of professional learning to strengthen teaching practices. Reading also helped participants feel more confident as a teacher and helped them respect opinions that are different from theirs. Professional development experiences helped participants feel more confident as a teacher by learning new teaching strategies and feel more confident in the classroom. Teachers' reading habits and their beliefs about reading may have a significant impact upon their students' motivation for and engagement in reading (Gambrell, 1996). Teachers become models for reading when they share their reading experiences with their students. Their reading habits have also been found to influence the instructional strategies they used in their classrooms. Morrison, Jacobs, and Swinyard (1999) claim that teachers' instructional strategies may be affected by their reading habit. Teachers who are enthusiastic readers tend to use instructional strategies (e.g., discussion groups and debates) that promote students' engagement in learning (Applegate \& Applegate, 2004).

Spending time in nature. The results of the narrative data analysis revealed that participants mostly associated spending time in nature with emotional and mindful attributes. Participants highly valued spending time in nature and in their narratives they associated spending time in nature with appreciating the natural world; being aware of and have ways to satisfy oneself; taking

Table 1

Themes and experiences within Personal Attributes.

\begin{tabular}{|c|c|c|}
\hline Themes & Words and expressions of participants & Experiences \\
\hline Crossing frontiers & $\begin{array}{l}\text { Venturing out and visiting new and different place; cultural exchange; broadening one's perspectives through experiences } \\
\text { and observing novel and different places, events, and lifestyles. }\end{array}$ & - Travelling \\
\hline Branching out & $\begin{array}{l}\text { To expand; to go into new areas; to become involved in a wider range of activities that will contribute to personal and } \\
\text { professional repository of knowledge and experience; to find opportunities to expand professional knowledge; to be open } \\
\text { to continuous learning and view challenges as opportunities to grow. }\end{array}$ & $\begin{array}{l}\text { - } \text { Reading } \\
\text { - Professional } \\
\text { development }\end{array}$ \\
\hline Enjoying life & $\begin{array}{l}\text { To appreciate the natural world; to be aware of and have ways to satisfy oneself; to take pleasure in creating and collecting; } \\
\text { to enjoy the moment; to unwind. }\end{array}$ & $\begin{array}{l}\text { - Spending time in } \\
\text { nature } \\
\text { - Having hobbies }\end{array}$ \\
\hline $\begin{array}{l}\text { Being unique and } \\
\text { different }\end{array}$ & $\begin{array}{l}\text { To pursue being original and different from others (e.g., siblings and peers) in the same community; to make different } \\
\text { choices than others in the same community; to value spending time alone. }\end{array}$ & $\begin{array}{l}\text { - Finding a space of their } \\
\text { own } \\
\text { - Leaving home at an } \\
\text { early age }\end{array}$ \\
\hline Persisting & $\begin{array}{l}\text { To purposefully pursue a course of action in spite of opposition; to follow one's individual endeavors despite the opposing } \\
\text { conditions or people. }\end{array}$ & $\begin{array}{l}\text { - Striving for education } \\
\text { - Not giving up on one's } \\
\text { endeavors }\end{array}$ \\
\hline
\end{tabular}


pleasure in creating and collecting; enjoying the moment; unwinding, building peace, serendipity, and tolerance, reducing stress and staying calm, triggering creativity, and building a positive culture. This finding is consistent with some literature. Interacting with nature may provide positive benefits amongst which psychological well-being and physical health are particularly noticeable. Interacting with nature may have positive contributions to individuals' psychological well-being (Berman et al., 2012); behaviors, academic performance and social skills in children (Keniger, Gaston, Fuller \& Irvine, 2013). Spending time in nature (e.g., interacting with nature through nature walks) may have cognitive and affective benefits for individuals suffering from depression (Berman et al., 2012). These arguments hold significant implications for the finding of this study as four participants (Ada, Gülşen, Pelin, Ekin Su) were brought up in either villages or nearhome nature environment. The teachers in this study could relate to how spending time in nature helped them to understand the importance of a positive classroom culture and peaceful atmosphere. Participants also used natural resources as teaching materials. They considered field trips as valuable learning opportunities as field trips helped build closer connections with their students.

Having hobbies. The results of the narrative data analysis indicated that participants associated having hobbies with discovering oneself and improving creativity. The results of narrative data analysis showed that participants associated hobbies with keeping motivated and energized, thinking flexibly, learning about other cultures and parts of the World, and building empathy and understanding toward people from different cultures. In the literature, having hobbies are associated with happiness (Costa, Paul, \& McCrae, 1980) and life satisfaction (Lu \& Hu, 2005). Most people associate leisure activities with "relaxation, enjoying life, selfgrowth, filling the time, social interaction, and health promotion" (Lu \& Hu, 2005, p. 2). This finding is consistent with the finding of this study as participants mostly considered hobbies as a way to keep calm and happy. The teachers in the study could identify how hobbies may have influenced their teaching practice. Hobbies fostered participants' creativity and imagination and they used hobbies to make learning fun for the students. Participants also stated that their (teachers') hobbies can be inspirational for the students and the students can get motivated and have their own hobbies.

\section{Discussion}

The findings from this study hold worthwhile implications for practice for teacher education programs and teacher educators. The first is the suggestion to integrate elements of certain constructive life experiences, which were reported to contribute to effective teaching dispositions, into teacher education programs. As the findings of the study revealed, the experiences of travelling, reading, spending time in nature, and having hobbies have potentially contributed to habits of mind that support effective teaching dispositions and their teaching practices. For instance, considering the positive impact of spending time in nature on individuals' psychological well-being, teacher education programs can provide opportunities for pre-service teachers to research about these impacts and experience spending time in nature perhaps through field trips or spending time in nature either during breaks or organizing short walks in nature. Likewise, the impacts of reading on teachers' knowledge and instructional strategies have been researched and some literature was discussed in previous sections. In addition to experiences in nature, the authors were able to find literature related to reading skills and teaching practice. Other experiences, especially travelling and having hobbies, were less prevalent in the research and need further investigation.
When teachers' dispositions are viewed as malleable entities, life experiences can be used as strategies to develop effective dispositions (Diez, 2007a; 2007b). The four attributes can be seen as the life experiences that can be offered in teacher education programs to develop future effective teaching dispositions. These experiences are recommended with the understanding that the environment of teacher education program should be taking into consideration just as the family environments of the participants were supportive but disciplined. However, it should be noted that the research was not about dispositions per se, but that the studies go to show that it is feasible to have these experiences in teacher education.

\section{Conclusion}

As expressed at the beginning of this paper, students need teachers who can prepare them for living in the modern world. More than knowledge and skills, teachers need constructive dispositions to support student learning and classroom management. As noted by other researchers, teachers' dispositions are linked to their teaching practices (Diez, 2007a; Fang, 1996) and teachers' beliefs, knowledge, and characteristics have long-lasting impact on their instructional practices (Hong et al., 2011). For the purpose of this study, the authors viewed teachers' disposition as clusters of habits that are sixteen habits of mind. It is possible that there are more dispositions that a teacher may have, which are beyond the framework used for the current study.

Through narrative inquiry, the current study has shown how certain experiences may contribute to effective teaching dispositions as sixteen habits of mind. Other researchers and teacher educators, interested in developing positive teaching dispositions, may explore how these experiences can best be integrated into teacher education programs. While benefits some of the experiences, such as incorporating environmental education into teacher education, have been investigated in the literature (Grace \& Sharp, 2000; Tuncer et al., 2009; Yavetz, Goldman, \& Pe'er, 2013), other experiences such as travelling and having hobbies are less prevalent.

The five teachers who provided narratives for the current study are all experienced female professionals who live in the same region of Turkey. The list of teachers' significant life experiences could be extended if this study is replicated in a similar or different context. Different insights may be gained from teachers of different generations, genders, and demographics. Whatever the target population, the authors emphasize the importance of listening to teachers' stories and experiences; their narratives are key resources for the design of effective teacher education programs.

\section{References}

Allgood, S. M., \& Beckert, T. E. (2012). The role of father involvement in the perceived psychological well-being of young adult daughters: A retrospective study. North American Journal of Psychology, 14(1), 95-110.

Applegate, A. J., \& Applegate, M. D. (2004). The Peter effect: Reading habits and attitudes of teacher candidates. The Reading Teacher, 57, 554-563.

Altan, S., Lane, F. J., \& Dottin, E. (2017). Using Habits of Mind, intelligent behaviors and educational theories to create a conceptual framework for developing effective teaching dispositions. Journal of Teacher Education, 1-15. https://doi org/10.1177/0022487117736024.

Beattie, M. (2000). Narratives of professional learning: Becoming a teacher and learning to teach. Journal of Educational Enquiry, 1(2), 1-23.

Becker, W. C. (1964). Consequences of different kinds of parental discipline. In M. L. Hoffman, \& L. W. Hoffman (Eds.), Review of child development research (pp. 169-208). New York: Russell Sage Foundation.

Berman, M. G., Kross, E., Krpan, K. M., Askren, M. K., Burson, A., Deldin, P. J., et al. (2012). Interacting with nature improves cognition and affect for individuals with depression. Journal of Affective Disorder, 140(3), 300-305.

Borko, H., Liston, D., \& Whitcomb, J. (2007). Genres of empirical research in teacher education. Journal of Teacher Education, 58(1), 3-11. 
Brewer, W. F. (1986). What is autobiographical memory? In D. Rubin (Ed.), Autobiographical memory (pp. 25-49). Cambridge: Cambridge University Press.

Brophy, J., \& Good, T. L. (1986). Teacher behaviour and student achievement. In M. C. Wittrock (Ed.), Handbook of research on teaching (3rd ed., pp. 328-375). New York: Macmillan.

Bruner, J. (1990). Acts of meaning. Cambridge, MA: Harvard University Press.

Butt, R. L., Townsend, D., \& Raymond, D. (1990). Bringing reform to life. Cambridge Journal of Education, 20(3), 255-268.

Byrne-Armstrong, H. (2001). Whose show is it? The contradictions of collaboration. In H. Byrne Armstrong, J. Higgs, \& D. Horsfall (Eds.), Critical moments in qualitative research (pp. 106-114). Oxford: Butterworth Heinemann.

Cabrera, N. J., \& Tamis-Lemonda, C. S. (2013). Handbook of father involvement: Multidisciplinary perspectives. New York: Routledge.

Caena, F. (2011). Literature review: Quality in teachers' continuing professional development. European commission thematic working group 'professional development of teachers' Brussels. European commission. Retrieved from http://ec. europa.eu/dgs/education_culture/repository/education/policy/strategicframework/doc/teacher-development_en.pdf.

Carter, K. (1993). The place of story in the study of teaching and teacher education. Educational Researcher, 22(1), 5-18.

Cavendish, L. M. (2011). Stories of international teachers: A narrative inquiry about culturally responsive teaching. Unpublished doctoral dissertation. USA: University of Iowa. Retrieved from http://ir.uiowa.edu/etd/933.

Chan, E. Y. (2012). The transforming power of narrative in teacher education. Australian Journal of Teacher Education, 37(3), 111-127.

Chawla, L. (2010). Life paths into effective environmental action. The Journal of Environmental Education, 31(1), 15-26.

Clandinin, D. J., \& Connelly, F. M. (1990). Narrative, experience and the study of curriculum. Cambridge Journal of Education, 20(3), 241-253.

Clandinin, D. J., \& Connelly, F. M. (2000). Narrative inquiry: Experience and story in qualitative research. San Francisco: Jossey-Bass Publishers.

Clandinin, D. J., \& Huber, J. (2012). Narrative inquiry. In B. McGraw, E. Baker, \& P. P. Peterson (Eds.), International encyclopedia of education (3rd ed., Vol. 4, pp. 436-441). New York, NY: Elsevier.

Connelly, F. M., \& Clandinin, D. J. (1990). Stories of experience and narrative inquiry. Educational Researcher, 19(5), 2-14.

Costa, , Jr., Paul, T., \& McCrae, R. R. (1980). Influence of extraversion and neuroticism on subjective well-being: Happy and unhappy people. Journal of Personality and Social Psychology, 38(4), 668-678.

Costa, A. L., \& Kallick, B. (2000). Discovering and exploring habits of mind. Alexandria, VA: ASCD.

Costa, A. L., \& Kallick, B. (2014). Dispositions: Reframing teaching and learning. Thousand Oaks, CA: Corwin.

Court, D., Merav, L., \& Ornan, E. (2010). Preschool teachers' narratives: A window on personal-professional history, values and beliefs. International Journal of Early Years Education, 17(3), 207-217.

Creswell, J. W., Plano Clark, V., Gutmann, M., \& Hanson, W. (2003). Advanced mixed methods designs. In A. Tashakkori, \& C. Teddlie (Eds.). Handbook of mixed method research in the social and behavioral sciences (pp. 209-240). Thousand Oaks, CA: Sage Publications.

Cruickshank, D. R., Jenkins, D. B., \& Metcalf, K. K. (2009). The act of teaching. New York: McGraw-Hill, Inc.

Darling-Hammond, L. (2000). How teacher education matters. Journal of Teacher Education, 51(3), 166-173.

Darling-Hammond, L. (2006). Constructing $21^{\text {st }}$-century teacher education. Journal of Teacher Education, 57(3), 300-331.

Day, C., \& Leitch, R. (2001). Teachers' and teacher educators' lives: The role of emotion. Teaching and Teacher Education, 17(4), 403-415.

Dewey, J. (1922). Human nature and conduct: An introduction to social psychology. New York: Henry Holt \& Company.

Dewey, J. (1938). Experience and education. New York: Collier.

Dickinson, E. (2012). Addressing environmental racism through storytelling: Toward an environmental justice narrative framework. Communication, Culture \& Critique, 5, 57-74.

Diez, M. E. (2007a). Assessing dispositions: Context and questions. In M. Diez, \& J. Raths (Eds.), Dispositions in teacher education (pp. 183-201). Charlotte, NC: Information Age Publishing.

Diez, M. E. (2007b). Looking back and moving forward: Three tensions in the teacher dispositions discourse. Journal of Teacher Education, 58(5), 388-396.

Dottin, E. (2009). Professional judgment and dispositions in teacher education. Teaching and Teacher Education, 25, 83-88.

Dottin, E. S., \& Sockett, H. (2006). A Deweyan approach to the development of moral dispositions in professional teacher education communities. In H. Sockett (Ed.) Teacher dispositions: Building a teacher education framework of moral standards (pp. 27-47). New York: AACTE Publications.

Egberts, M. R., Prinzie, P., Dekovic, M., de Haan, A. D., \& van den Akker, A. L. (2015) The prospective relationship between child personality and perceived parenting: Mediation by parental sense of competence. Personality and Individual Differences, 77, 193-198.

Fang, Z. (1996). A review of research on teacher beliefs and practices. Educational Research, 38(1), 47-65.

Gambrell, L. B. (1996). Creating classroom cultures that foster reading motivation. The Reading Teacher, 50(1), 14-25.

Goleman, D. (1995). Emotional intelligence. New York: Bantam Books.

Goodson, I., \& Gill, S. (2014). Critical narrative as pedagogy. New York \& London:
Bloomsbury.

Grace, M., \& Sharp, J. (2000). Exploring the actual and potential rhetoric-reality gaps in environmental education and their implications for pre-service teacher training. Environmental Education Research, 6(4), 331-345.

Greenfield, P. M., \& Suzuki, L. K. (1998). Culture and human development: Implications for parenting, education, pediatrics and mental health. In W. Damon, R. M. Lerner, K. A. Renninger, \& I. E. Sigel (Eds.), Handbook of child psychology: Child psychology in practice (pp. 1059-1109). Hoboken, NJ: John Wiley and Sons.

Guba, E. G., \& Lincoln, Y. S. (1994). Competing paradigms in qualitative research. In N. K. Denzin, \& Y. S. Lincoln (Eds.), Handbook of qualitative research (pp. 105-117). Thousand Oaks, CA: Sage Publications.

Herlihy, J., Jobson, L., \& Turner, S. (2012). Just tell us what happened to you: Autobiographical memory and seeking asylum. Applied Cognitive Psychology, 26(5), 661-676.

Hong, E., Greene, M., \& Hartzell, S. (2011). Cognitive and motivational characteristics of elementary teachers in general education classrooms and in gifted programs. Gifted Child Quarterly, 55(4), 250-264.

Jarvis, P. (1987). Adult learning in the social context. London: Croom Helm.

Johnson, K. E., \& Golombek, P. (2002). Teachers' narrative inquiry as professional development. New York, NY: Cambridge University Press.

Keniger, L. E., Gaston, K. J., Irvine, K. N., \& Fuller, R. A. (2013). What are the benefits of interacting with nature? International Journal of Environmental Research and Public Health, 10, 913-935.

Knafo, A., \& Schwartz, H. S. (2004). Identity formation and parent-child value congruence in adolescence. British Journal of Development Psychology, 22, 439-458.

Kolb, D. A. (1984). Experiential learning: Experience as the source of learning and development. Englewood Cliffs, NJ: Prentice Hall.

Lamb, M. E. (2010). The role of the father in child development. New York: John Wiley and Sons.

Langelholf, M. R., Komdeur, J., \& Oldehinkel, A. J. (2016). Effects of parenting quality on adolescents' personality resemblance to their parents: The TRAILS study. Journal of Adolescence, 51, 163-175.

Lasley, T. J., Siendentop, D., \& Yinger, R. (2006). A systemic approach to enhancing teacher quality. Journal of Teacher Education, 57, 13-21.

Lindsay, G. M., \& Schwind, J. K. (2016). Narrative inquiry: Experience matters. Canadian Journal of Nursing Research, 48(1), 14-20.

Lu, L., \& Hu, C.-H. (2005). Personality, leisure experiences and happiness. Journal of Happiness Studies, 6, 325-342.

Mayer, J. D., \& Salovey, P. (1997). What is emotional intelligence? In P. Salovey, \& D. J. Sluyter (Eds.), Emotional development and emotional intelligence (pp. 3-31). New York: Basic Books.

McAdams, P. M. (2001). The psychology of life stories. Review of General Psychology, 5(2), 100-122.

Merriam, S. B., \& Clark, M. C. (1993). Learning from life experience: What makes it significant? International Journal of Lifelong Education, 12(3), 129-138.

Mezirow, J. (1990). How critical reflection triggers transformative learning. In J. Mezirow (Ed.), Fostering critical reflection in adulthood (pp. 1-20). San Francisco: Jossey-Bass Publishers.

Morrison, T. G., Jacobs, J. S., \& Swinyard, W. R. (1999). Do teachers who read personally use recommended literacy practices in their classrooms? Reading Research and Instruction, 38(2), 81-100.

Myers, M. (2000). Qualitative research and the generalizability question: Standing firm with Proteus. The Qualitative Report, 4(3), 3-9.

Nelsen, P. J. (2015). Intelligent dispositions Dewey, habits and inquiry in teacher education. Journal of Teacher Education, 66(1), 86-97.

Nettle, D. (2008). Why do some dads get more involved than others? Evidence from a large British cohort. Evolution and Human Behavior, 29(6), 416-423.

Orland-Barak, L., \& Maskit, D. (2011). Novices in story: What first year teachers' narratives reveal about the shady corners of teaching. Teachers and Teaching: Theory and Practice, 17(4), 435-450.

Polkinghorne, D. E. (1988). Narrative knowing and the human sciences. Albany, NY: State University of New York Press.

Polkinghorne, D. E. (2007). Validity issues in narrative research. Qualitative Inquiry, 13(4), 471-486.

Pressmen, S. D., Matthews, K. A., Cohen, S., Martie, L. M., Scheier, M., Baum, A., et al. (2009). Association of enjoyable leisure activities with psychological and physical well-being. Psychosomatic Medicine, 71(7), 725-732.

Riessman, C. K. (1993). Narrative analysis. Qualitative research methods series. Newbury Park, CA: Sage Publications.

Riessman, C. K. (2008). Narrative methods for the human sciences. Thousand Oaks, CA: Sage.

Ritchhart, R. (2001). From IQ to IC: A dispositional view of intelligence. Roeper Review, 23(3), 143-150.

Rosenberg, J., \& Wilcox, W. B. (2006). The importance of fathers in the healthy development of children. Washington, DC: U.S. Department of Health and Human Services. Children's Bureau. Retrieved from Youth and Families Children's Office on Child Abuse and Neglect website http://nccanch.acf.hhs.gov/profess/tools/ usermanual.cfm.

Sandelowski, M. (1991). Telling stories: Narrative approaches in qualitative research. Journal of Nursing Scholarship, 23(3), 161-166.

Secunda, V. (1992). Women and their fathers. New York: Bantam Doubleday Dell.

Serdyukov, P., \& Ferguson, B. T. (2011). Teacher dispositions: What kind of candidates do we have in a teacher education program and how do we make them better? Journal of Research in Innovative Teaching, 4(1), 106-119. 
Spector-Mersel, G. (2011). Mechanisms of selection in claiming narrative identities: A model for interpreting narratives. Qualitative Inquiry, 17(2), 172-185.

Stake, R. E. (1978). The case study method in social inquiry. Educational Researcher $7(2), 5-8$.

Suzuki, T. (2005). Relationship between two aspects of perfectionism and obsessive- compulsive symptoms. Psychological Reports, 96, 299-305.

Tellez, K., \& Waxman, H. (2006). Preparing quality educators for English language learners: Research, policies \& practices. London: Lawrence Erlbaum Associates.

Thornton, H. (2006). Dispositions in action: Do dispositions make a difference in practice? Teacher Education Quarterly, 33(2), 53-68.
Tuncer, G., Tekkaya, C., Sungur, S., Cakiroglu, J., Ertepinar, H., \& Kaplowitz, M. (2009). Assessing pre-service teachers' environmental literacy in Turkey as a mean to develop teacher education programs. International Journal of Educational Development, 29, 426-436.

Vazire, S. (2010). Who knows what about a person? The self-other knowledge asymmetry (SOKA) model. Journal of Personality and Social Psychology, 98 281-300.

Yavetz, B., Goldman, D., \& Pe'Er, S. (2013). How do preservice teachers perceive 'environment' and its relevance to their area of teaching? Environmental Education Research, 20(3), 354-371. 